\title{
RELACIONAMENTO ENTRE BUROCRACIA E PÓS-BUROCRACIA EM UM CONTEXTO DE DOMINAÇÃO, CONTROLE E PODER: UM ENSAIO TEÓRICO
}

\author{
RELATIONSHIP BETWEEN BUREAUCRACY \\ AND POST-BUREAUCRACY IN A CONTEXT OF \\ DOMINATION, CONTROL AND POWER: A THE- \\ ORETICAL ESSAY
}

\section{RESUMO}

O presente ensaio teórico tem como objetivo relacionar a burocracia à pós-burocracia, utilizando-se dos conceitos de dominação, controle e poder. O referencial teórico aborda conceitos citados, focando na burocracia em Kalberg (2010) e Weber (2012) e sua pretendente a sucessora a teoria pós-burocrática, tomando o serviço público como contexto. Por fim, realizou-se uma discussão do referencial, encontrando na pós-burocracia a existência de controle coercitivo, exercido pelos pares que apresenta ainda maior rigidez que nos ambientes burocráticos. $\mathrm{O}$ argumento central mediante discussão é de que não ocorreu ruptura entre burocracia e pós-burocracia no serviço público, estando ele com características

Jair Jeremias Junior jair.jeremias.j@gmail.com Doutorando em Administração pela Universidade Federal do Rio Grande do Sul. Porto Alegre $-R S-B R$

Anelise Pessi anepessi85@gmail.com Especialização em MBA Profissional: Gestão Pública e Responsabilidade. Graduada em Administração. Universidade Federal da Integração Latino-Americana Foz do Iguaçu-PR-BR.

Arthur Gehrke Martins de Andrade arthur_gma@hotmail.com Mestrando em Administração pela Universidade Federal do Rio Grande do Sul. Porto Alegre $-R S-B R$. híbridas inerentes à burocracia e às diversas iniciativas pós-burocráticas. Como sugestão para estudos futuros, sugere-se a exploração empírica desse contexto por tratar-se de ambiente com característica adequada para tal, bem como relacionar com estudos que abranjam as teorias de carreira trazendo um olhar por meio dos praticantes.

Palavras-chave: Burocracia. Pós-burocracia. Dominação. Serviço Público.

\begin{abstract}
This theoretical essay aims to relate bureaucracy to post-bureaucracy, using the concepts of domination, control and power. The theoretical framework addresses concepts cited, focusing on bureaucracy in Kalberg (2010) and Weber (2012) and their suitor to successor the post-bureaucratic theory, taking public service as context. Finally, there was a discussion of the referential, finding in post-bureaucracy the existence of coercive control, exercised
\end{abstract}


by peers that presents even greater rigidity than in bureaucratic environments. The central argument in the discussion is that there was no rupture between bureaucracy and post-bureaucracy in the public service, as it has hybrid characteristics inherent to bureaucracy and the various post-bureaucratic initiatives. As a suggestion for future studies, it is suggested that the empirical exploration of this context be carried out, since it is an environment with adequate characteristics for this, as well as relating to studies that cover career theories by bringing a look through the practitioners.

Keywords: Bureaucracy. Post-bureaucracy. Domination. Public Service.

\section{INTRODUÇÃO}

Diversos estudos desenvolveram uma abordagem mediante dominação, controle e poder, considerando suas mais diversas faces e possibilidades (HERMAN et al., 1981; VIEIRA, 1997; COURPASSON, 2000; KALBERG, 2010). Destacam-se os estudos da sociologia de Weber ao dispor sobre estruturas de organizações, entendendo a burocrática como possível modelo ideal que aborda suas características e relações de poder, podendo destacar seu ideal de legitimidade para ser efetivado o contexto de dominação, que se daria por meio de três princípios: racional, tradicional e carismático (KALBERG, 2010; WEBER, 2012, p. 141).

O homem é considerado um ser social com possibilidade de escolha, que se dá, por meio de uma multiplicidade de fatores, desde individuais a condicionantes sociais. Tal entendimento vai ao encontro da teoria comportamental, caracterizada por abordagens que privilegiam as estruturas sociais, e também difere de todas as visões positivistas que atribuem a normas papéis e regras uma força determinante sobre as pessoas (KALBERG, 2010). Decorrendo disso a definição dos quatro tipos de ações sociais, classificadas em quatro grupos: racional referente a fins; racional referente a valores; afetiva e tradicional (KALBERG,
2010; WEBER, 2012, p. 15). Conforme Weber (2012, p. 138), a dominação determinada por um grupo de pessoas é um dos elementos mais importantes da ação social, porém, ressalta o autor, nem toda ação social implica dominação.

Discorre-se sobre a burocracia como um tipo de organização com característica de sistematização da organização do trabalho, com base em regulamentos e regras. Decisões menos ambíguas, jurisdição, especialização de funções, competências e responsabilidades definidas, de um lado, por regulamentos administrativos e, de outro, por treinamento técnico que ressaltam a neutralidade e impessoalidade características deste modelo. A dominação, inclusive a possibilidade de o superior fazer uso de meios coercitivos, é distribuída de maneira estável e articulada por regulamentos (KALBERG, 2010; WEBER, 2012, p. 46).

Enquanto a pós-burocracia, composta, segundo Vasconcelos (2004), por organizações simbolicamente intensivas, produtoras de consenso por meio da institucionalização do diálogo. As características seriam autonomia, aprendizagem, flexibilidade, confiança e diálogo, bem como alteração no que tange à obtenção de legitimidade e próprio controle que acaba como de responsabilidade dos pares (BARKER, 1993).

Neste passo, o contexto do serviço público aparece como cenário rico para exploração do proposto no artigo seja pelas estruturas burocráticas, seja pelas tendências mais atuais para a pós-burocracia. Esse ensaio teórico tem como principal objetivo apresentar uma contribuição teórica que possibilite uma aproximação relacional entre as estruturas burocráticas e as estruturas pós-burocráticas por meio das conceituações e da explicação do contexto de dominação, do controle e poder inerentes a esses tipos de organizações, tendo como referencial a literatura da teoria das organizações, explorando o contexto do serviço público.

Para tal, partimos da apresentação das faces de dominação, controle e poder nas organizações, focando a teoria burocrática criada por Weber e sua pretendente à sucessora, a 
teoria pós-burocrática, enfatizando seus principais conceitos e características. Por fim, será realizada uma análise relacional entre os temas, com o intuito de obter uma contribuição teórica que possibilite melhor entendimento dos estudos referentes a essa relação.

\section{DOMINAÇÃO, CONTROLE E PODER}

Inúmeros estudos sobre dominação foram realizados ao longo do tempo, considerando sua forte relevância, comprovada por terem sido fonte de inúmeros debates. Nesse campo, foram estabelecidas diversas classificações de dominação, como a de Courpasson (2010), que vê como meio político de construção de ordem social que produz eficiência para aqueles no poder e seus subordinados ou em uma linha mais Weberiana, em que Sousa e Paiva Junior (2010) trazem como sentido de autoridade racional-legal que se divide com base na legitimidade de suas ordens, baseadas, principalmente, em tradições ou carisma.

Kalberg (2010) constrói uma interpretação dos escritos de Weber, em que dominação não é vista como um fato social, uma expressão de leis "naturais" ou a inevitável culminação de forças evolutivas históricas, mas tão somente a probabilidade de que um grupo determinável de indivíduos oriente sua ação social ao emitir ordens, somada à probabilidade de que outro grupo, também determinável, oriente sua ação social para a obediência, e que as ordens sejam, de fato, cumpridas em um nível tido como sociologicamente relevante. Portanto, propôs um conceito de dominação que diz respeito às chances de encontrar obediência a uma ordem, de determinado grupo de pessoas (KALBERG, 2010; WEBER, 2012, p. 139).

Weber (2012, p. 139) associa dominação à legitimidade, buscando explicar o porquê de a obediência configurar-se como uma característica voluntária. Kalberg (2010) ressalta que a natureza de crença típica, ou pretensão à legitimidade, é o critério usado por Weber (2012, p. 139) para classificar os principais tipos de dominação legítima em modelos típico-ideais. Weber (2012, p. 141) aborda as crenças típicas que fundamentam a validade desses três tipos puros de dominação legítima:

a) um princípio racional, isto é, a crença na legalidade de regras sancionadas e no direito dos que são alçados à dominação sob tais regras a emitir ordens (dominação legal);

b) um princípio tradicional, isto é, na crença estabelecida na santidade de tradições imemoriais e na legitimidade dos que exercem a dominação sob tais tradições (dominação tradicional);

c) um princípio carismático, isto é, a devoção afetiva à santidade, heroísmo ou caráter exemplar de uma pessoa, e às revelações ou ordenações por ela emitidas (dominação carismática).

Weber (2012, p. 147) ressalta que, quando a ação social de uma formação de dominação está baseada em uma relação associativa racional, encontra seu tipo específico na burocracia, por meio de uma autoridade burocrática e de uma empresa burocrática. Essa dominação é mantida por meio do que o autor denomina de "vantagem do pequeno número", isto é na possibilidade existente da minoria dominante de comunicar-se internamente com rapidez, dando origem, a cada momento, a uma ação social racionalmente organizada que busca a conservação da posição de poder. Assim sendo, a "vantagem do pequeno número" é eficaz quando os dominadores guardam segredo de suas intenções, decisões e conhecimentos, tendo em vista que "toda dominação que pretenda continuidade é, em algum ponto decisivo, dominação secreta." (WEBER, 2012, p. 147).

Com relação ao poder, Courpasson (2000) o entende como instrumento de estruturas de dominação, cujo objetivo é construir, justificar e estabilizar a obediência do pessoal, sendo a ordem organizacional baseada na confiança-obediência. Já Medeiros (2006) vê a organização como uma arena e interesses e valores conflitantes, constituída pela luta de poder, 
enquanto Machado-da-Silva e Coser (2006) entendem que as relações de poder seriam reforçadas, mantidas ou reproduzidas por meio do esforço dos atores em determinar valores, crenças, regras e conceitos a serem compartilhados e legitimados no campo organizacional e que reforcem um modus operandi que dê continuidade ao poder conquistado. Em abordagens que relacionam controle a poder, Herman (1981) trata da capacidade de iniciar, restringir, circunscrever ou concluir a ação diretamente, ou por influência exercida naqueles com autoridade para tomada de decisão imediata e, para Vieira (1997), fala em potencial de uma unidade social determinar o comportamento de outra.

Outro ponto associado ao tema seria o da construção da identidade na organização como um fenômeno que trata do fazer sentido da organização Weber e Glynn (2006), pelo entendimento que homens são seres sociais, e a realidade é socialmente construída, tendo o empregado uma percepção de como ele se vê dentro a organização, podendo gerar maior ou menor identidade que, por sua vez, pode influenciar em fatores como o comprometimento e até legitimidade da autoridade, envolvendo nessas relações, segundo Alvesson e Willmott (2002) a regulação da identidade, identidade do trabalhador e autoidentidade.

Para Kalberg (2010), Weber parte de um pressuposto de que as pessoas realizam uma compreensão interpretativista de suas realidades sociais, atribuindo sentido subjetivo a determinados aspectos, afirmando a possibilidade de escolha. Tal entendimento decorre da definição de Sociologia em Weber (2012, p. 3) como ciência que pretende compreender, interpretativamente, a ação social e explicá-la, causalmente, em seu curso e em seus efeitos. Em uma análise da percepção da ação social, definida em Weber (2012, p. 3) como uma ação que, quanto a seu sentido visado pelo agente, refere-se ao comportamento de outros, orientando-se por este em seu curso, frisa-se que as pessoas são vistas como seres sociais e não apenas sociais, admitindo a possibilidade de influência do agente individual nas decisões para ação, vinculado a um sentido subjetivo de seu comportamento na mesma linha de pensamento que acredita o ambiente de organização também ser socialmente construído (SMIRCICH; STUBBART, 1985).

Por meio da definição de Weber (2012, p. 3) de ações sociais, estas são classificadas em quatro grupos, correspondendo cada uma delas a um tipo ideal de orientação motivacional dos agentes:

a) ação racional referente a fins (zweckational): aquela em que são levados em conta e racionalmente ponderados os "fins", os meios e as consequências;

b) ação racional referente a valores: determinada por uma crença consciente no valor em si de uma conduta ética, estética, religiosa ou de outra nature$\mathrm{za}$, independentemente das perspectivas de sucesso;

c) ação afetiva: determinada por afetos e estados sentimentais atuais do "agente"; implica apego emocional;

d) ação tradicional: determinada por hábitos arraigados e costumes seculares, quase sempre uma resposta meramente rotineira a estímulos comuns, situa-se na fronteira da ação dotada de sentido subjetivo.

Kalberg (2010) aduz que a ideia de contribuição por meio de um avanço na compreensão da ação social do ponto de vista das intenções do próprio agente destaca o pluralismo de motivos que distingue tal abordagem de todas as escolas comportamentais, abordagens que privilegiam as estruturas sociais, e de todas as visões positivistas que atribuem a normas, papéis e regras uma força determinante sobre as pessoas, sendo, nessa teoria, possível explicar as causas de casos individuais por meio de configurações igualmente individuais.

\subsection{BUROCRACIA E PÓS-BUROCRACIA}

Burocracias organizam o trabalho sistematicamente, tendo em vista regras e regulamentos gerais. As decisões burocráticas são 
menos ambíguas, jurisdição, especialização de funções, competências e responsabilidades definidas, de um lado, por regulamentos administrativos e, de outro, por treinamento técnico. A dominação, inclusive a possibilidade de o superior usar meios coercitivos, é distribuída de maneira estável e articulada por regulamentos (KALBERG, 2010). Segundo Crozier, independentemente dos problemas e das disfunções do sistema, a burocracia é um sistema que tem sua funcionalidade e sua lógica próprias. A burocracia é uma solução organizacional que tentaria evitar a arbitrariedade, o confronto entre os indivíduos e grupos e os abusos de poder (VASCONCELOS; PINOCHET, 2004).

Das instituições racionais legais, a burocracia é entendida como tipo puro de dominação, tendo como características a impessoalidade, a normatização, a hierarquia, legitimidade, o controle dos empregados realizado por supervisores, a sistematização dos procedimentos e as atividades e especialização, tendo inúmeras vantagens e desvantagens decorrentes de sua utilização, mas tornando a organização menos propícia a responder às mudanças que possam ocorrer no ambiente competitivo, denominada por Max Weber de "Iron Cage", explorada no estudo de (BARKER, 1993).

Segundo Kalberg (2010) e Weber (2012, p. 145-146), o modelo weberiano da dominação "racional-legal" manifesta-se na organização burocrática, e sua legitimidade repousa na crença em regras devidamente estatuídas e em normas procedimentais "objetivas", não em pessoas ou em tradições estabelecidas no passado. Weber (2012, p. 144), por meio de sua teoria dos tipos ideais, estabelece características do denominado "funcionário burocrático" que identifica orientações padronizadas para a organização disciplina do trabalho, a pontualidade, confiabilidade, especialização de funções e a cadeia hierárquica de comando; e o tipo ideal do "líder carismático" delineia orientações com relação a pessoas consideradas extraordinárias e a disposição de outros a segui-los, mesmo que seja necessário infringir a convenção e o costume (KALBERG, 2010).
Em decorrências das novas necessidades e alterações contextuais nas relações sociais, nasce a chamada pós-burocracia, em que são criadas equipes autogerenciáveis que assumem as responsabilidades de seus supervisores, assim como definem o que devem fazer, quando devem fazer; todos são treinados para realizar diversas atividades, tornando a organização mais propícia a dar respostas mais rápidas às mudanças de contexto, sendo as definições referentes a normas, valores e objetivos consensuais, passando o controle a ser exercido pelos pares e não pelos supervisores que não mais existem, tornando o controle cada vez maior à medida que os valores da organização se tornem mais enraizados nos empregados (BARKER, 1993).

Segundo Vasconcelos (2004), a pós-burocracia é composta por organizações simbolicamente intensivas, produtoras de consenso por meio da institucionalização do diálogo, sendo mais especificamente categorizadas pelas seguintes características:

a) constituir grupos de trabalho flexíveis e constituir forças-tarefa temporárias com objetivos claros;

b) criar espaços para diálogo e conversação;

c) enfatizar confiança mútua;

d) usar o conceito de missão como ferramenta estratégica;

e) disseminar informação, criar redes de difusão e recuperação de conhecimento;

f) criar mecanismos de feedback e avaliação de performance por meio de revisão pelos pares;

g) criar capacidade de resiliência e flexibilidade na organização.

Segundo Barker (1993), proponentes de equipes autogerenciáveis as têm descrito como uma mudança radical no modelo gerencial tradicional de estrutura de autoridade de uma organização. Pós-burocráticos afirmam que estruturas de gerenciamento tradicionais requerem inflexibilidades hierárquicas e restrições burocráticas que reprimem criatividade e inovação. 
Organizações rígidas são pesadas com gerentes e mudanças sem respostas, mercados dinâmicos, ultimamente reduzindo sua viabilidade competitiva, eliminando supervisores desnecessários e outras equipes burocráticas. A perspectiva de autogerenciamento propõe uma mudança radical de supervisão hierárquica para entrega, ao gerenciamento colaborativo do trabalhador.

Para Vasconcelos (2004), uma organização com reais características pós-burocráticas somente seria viável, a fim de cumprir todos os requisitos inerentes a ela: de autonomia, aprendizagem, flexibilidade, confiança e diálogo, caso fosse redefinido o critério de legitimidade que a suporta. Isso implicaria compreender como se dão os processos de institucionalização do carisma, as dinâmicas de liderança, a motivação, o comprometimento e o trabalho em grupo de uma forma mais profunda, uma vez que esses elementos, subsidiários para o modelo burocrático, são centrais para o funcionamento de organizações no modelo pós-burocrático.

Um campo de estudo que aborda tanto burocracia, como pós-burocracia é o serviço público, em que Keinert (1999) divide a história da Administração Pública - AP em quatro períodos paradigmáticos, encontrados a partir da evolução do conceito de público, citando o Paradigma Público enquanto Estatal (1930-79), em que predomina uma relação entre estado e sociedade estadocêntrica e um estilo de gestão pública burocrático. A década de 1980 é tida como um período de crise. No pós 1990, surge o Paradigma Emergente do Público enquanto Interesse Público em uma relação estado e sociedade tida como sociocêntrica, com estilo de gestão pública pós-burocrático (KEINERT, 1999). Focando no último período paradigmático, Keinert (1999) cita as rápidas mudanças observadas na sociedade que colocam a exigência de se repensar o papel do Estado, considerando-se os avanços da tecnologia da informação, que colocam questões como agilidade, rapidez, flexibilidade, competitividade e, especialmente, qualidade nos serviços e produtos na ordem do dia. Segundo a autora, isso demanda, sem dúvida, um novo Estado, novos valores, novos serviços e novos servidores públicos.

A ideia de AP burocrática começa a tomar forma no país após 1929, tendo substituído um modelo predominante até então com raízes paternalistas (KEINERT, 1999). Neste passo, Cavalcante e Carvalho (2017) citam que as ações da AP são subordinadas aos governos, sejam eles eleitos ou não, argumentando que, quanto mais autônoma, com relação a seu sistema de mérito, estabilidade e remuneração adequada, menores seriam as chances de arbitrariedade e interferência de critérios fisiológicos e particularistas, de modo a refletir na capacidade da AP de formular e implementar políticas públicas. Nesse sentido, foram estabelecidas medidas na ideia de se superar o clientelismo e paternalismo no serviço público.

Na década de 1990, a AP passa por diversas mudanças oriundas da abertura da economia, alteração da Constituição de 1988, criação do regime jurídico único para servidores públicos, instituição do concurso público como único meio de ingresso em cargo público efetivo, inviabilizando a ascensão vertical entre cargos, além da reforma administrativa de 1995. Bresser -Pereira (1996) tinha, na reforma administrativa, o objetivo de reconstrução do Estado brasileiro, por meio de uma ampla reestruturação (com descentralização, privatização e valorização da esfera pública não governamental), do controle fiscal e da implantação de técnicas gerenciais que melhorassem a performance do Estado, uma virada da AP burocrática para a AP gerencial.

No âmbito da reforma administrativa, preceitos são denominados de Nova Administração Pública - NAP, que, para Andion (2012), é um movimento que teve grande influência; por um lado, por ser um modelo normativo, formado por um conjunto de abordagens teóricas que se complementam, permitindo uma compreensão da esfera pública e seu funcionamento, por meio dos princípios mercadológicos, norteada pela incorporação de tecnologias da gestão do setor privado para o setor público. Ainda, surge, entre os estudos no âmbito da AP, o Novo Serviço Público - NSP, como contraponto às correntes estadocêntrica e da NAP, tendo como 
base uma gestão com base em teorias democráticas e da cidadania, os modelos de comunidade e sociedade civil, humanismo organizacional e teoria de discurso, em uma abordagem caracterizada pela coprodução do bem público em que o usuário não é visto como cliente ou simples beneficiário, tornando o cidadão protagonista na prestação do serviço público e na promoção da transformação social (ANDION, 2012).

Depreende-se que, no contexto da AP, a noção de Administração Burocrática aparece como substitutiva de um modelo paternalista que não apresentava resultados efetivos para população, bem como a ideia traçada por Bresser-Pereira (1996) para a reforma administrativa de 1995, perpassa uma intenção movimento semelhante de ruptura da administração burocrática para uma gerencial, que, além de tecnologias e métodos da iniciativa privada, estaria aberta para a coprodução do bem público, em que a população atuaria ativamente do fazer público em uma vertente associada à ideia da teoria da pós-burocracia. Contudo, Souza (2017), em sua análise, verifica que a burocracia federal brasileira ainda possui as principais características de uma burocracia weberiana.

\section{RELAÇÃO ENTRE BUROCRA- CIA, PÓS-BUROCRACIA E O CONTEXTO DE DOMINAÇÃO, CONTROLE E PODER}

Segundo Vasconcelos e Pinochet (2004), a organização é vista como um sistema de jogos estruturados. As regras e estruturas organizacionais operam de modo indireto e não determinam o comportamento dos atores sociais, mas induzem certos tipos de jogos de poder e comportamentos. Os atores sociais podem colaborar ou não colaborar, buscando negociar melhores condições de inserção no sistema e obter um maior controle de recursos, atendendo a seus objetivos e interesses pessoais. No entanto, ao lutar pela realização de seus interesses pessoais, os atores sociais devem jogar a partir das opções fornecidas pelo sistema e, dessa forma, estarão, mesmo dentro de um nível mí- nimo, cumprindo em parte os objetivos organizacionais. Nessa linha, está a ideia Weberiana com relação ao homem como um ser social, a possibilidade de escolha, seja para agir decorrente de interesses próprios, seja por influência do meio. Esse conceito de escolha e visão do homem como ser social de certa forma reforça o posicionamento de Weber quanto à necessidade de legitimidade para a criação de um contexto de dominação (KALBERG, 2010; WEBER, 2012, p. 139). Somada essas ideias aos autores citados neste ensaio, perpassa a linha de que a estrutura influencia as ações das pessoas; contudo, as ações das pessoas também podem ter o poder de influenciar a ação dos outros e, portanto, na estrutura, em uma inter-relação constante que pode levar tanto à manutenção, como à alteração do status quo.

Weber (2012, p. 144) discorre sobre a possibilidade existente da minoria dominante de comunicar-se internamente com rapidez, dando origem, a cada momento, a uma ação social racionalmente organizada que busca a conservação da posição de poder. Disso, percebe-se a ideia de perpetuação, continuidade da relação dominante, dominado e conservação do status quo. Enquanto a pós-burocracia, para Vasconcelos (2004), é composta por organizações simbolicamente intensivas, produtoras de consenso por meio da institucionalização do diálogo, autogerenciáveis, com decisões colegiadas e controle entre os pares, que, ao propiciar uma maior participação e processos de cocriação, tenderiam a minimizar a existência dessas minorias dominantes.

Para Barker (1993), organizações pósburocráticas demonstram um controle exercido pelos pares, denominado de "controle coercitivo", em que cresce um consenso substancial de valores, coordenação de alto nível e um grau de autogerenciamento pelos membros ou trabalhadores em uma organização. Complementando e reforçando o afirmado por Barker (1993), nos estudos de Dellagnelo e Machado-da-Silva (2000) acerca das instituições pós-burocráticas, constatou-se que, em termos de formação da identidade, é marcante a presença de fortes va- 
lores compartilhados pelos membros organizacionais, restando pequena margem para maior variabilidade interna. Convertida para equipes de autogerenciamento, a estrutura coercitiva resultou em uma forma de controle mais poderosa, menos aparente e mais difícil de resistir que a forma anterior de burocracia. Para Dimaggio e Powell (2005), a imagem da gaiola de ferro começou a assombrar os estudiosos e a sociedade à medida que o ritmo da burocratização se acelerava, processo esse que tornava as organizações mais similares, contudo sem as tornar mais eficientes. A ironia citada pelo autor é que a mudança para características pós-burocráticas, ao contrário de destruir a gaiola de ferro do controle racional baseado em regras, como chamado por Max Weber, na verdade, tornou-a mais apertada.

Se tomarmos como exemplo o tópico inovação, tão presente no cotidiano, verifica-se que estruturas burocráticas tendem a restringi-la, enquanto características pós-burocráticas possam estimulá-las. A própria noção de legitimidade para exercício da dominação, controle e poder sofre alterações significativas conforme a característica adotada. Com relação ao aspecto da identidade, apesar de não ser objeto do presente estudo, faz-se interessante verificar por meio das trajetórias dos servidores públicos, pessoas que vivem esse contexto diariamente, como se dá a noção de identidade, considerando o contexto sócio-histórico de mudanças por que passou e passa a AP, trazendo contribuições à literatura por apresentar um olhar a partir da perspectiva do indivíduo para o problema, alterando o foco na estrutura ou organizações.

Em complemento à possível evolução sugerida de organizações da teoria burocrática para a pós-burocrática, Vasconcelos (2004) tem o mesmo posicionamento que Dellagnelo e Machado-da-Silva (2000), entendendo que o modelo pós-burocrático não realizou ruptura do modelo burocrático tradicional por não ter se desvinculado da autoridade racional-legal. Para o contexto público Souza (2017), também entende como caracterizada pela burocracia Weberiana, evidenciando com isso posicionamen- to semelhante. Tal cenário evidencia fronteiras cada vez mais borradas, tendo em vista a clara intencionalidade presente em Bresser-Pereira (1996) de transição de um modelo burocrático para o gerencial, trazendo características da administração privada para o contexto público e princípios alinhados à pós-burocracia.

Ocorre que, atualmente, a AP brasileira demonstra-se como contexto híbrido, com características do modelo burocrático como afirmado em Souza (2017) que convivem com cada vez mais iniciativas associadas ao conceito da pós-burocracia, a exemplo dos portais da transparência, elaboração de orçamentos participativos, parcerias com organizações civis ou mesmo estruturas de decisões colegiadas tão comuns nas universidades do país. Nesse passo, Cavalcante (2019) cita que o atual papel da AP é focar em direção de habilidades interdisciplinares, capacidades colaborativas, transparência na prestação de contas com a sociedade, bem como liderança com componentes interativos. Tal cenário propicia um ambiente cada vez mais complexo e variado com relação às relações de poder, dominação e controle, mas muito rico para a exploração empírica que contribua à literatura.

\section{CONCLUSÃO}

No estudo em questão, discorremos sobre burocracia e pós-burocracia por meio de conceitos de dominação, controle e poder. Ao abordar as estruturas burocráticas e pós-burocráticas, percebe-se que a conceituação de Weber ainda tem grande validade para os estudos, reforçada ao ser referenciado por grande maioria dos estudos da área. Verificou-se, como consequências da adoção de estrutura pós-burocrática, um nível de controle muito superior, ao eliminar a figura do supervisor presente na estrutura burocrática, para o controle exercido pelos pares. Outro ponto a ser considerado é de que, justamente por as decisões serem tomadas de maneira consensual, apesar de terem conotação mais forte, pode ocasionar um maior índice de rejeição por parte de colaboradores que não 
tenham identificação com a organização, bem como propiciam uma alteração no entendimento de legitimidade que tende a ter bases mais coletivas para a tomada de decisão, restringindo a atuação de certos tipos de dominação associadas, principalmente, a elementos mais tradicionais, por exemplo.

A ideia de que não houve ruptura do modelo burocrático para o pós-burocrático na AP é corroborada por Vasconcelos (2004) ao citar que, efetivamente, não ocorrerá tal transposição, mas sim uma adaptação do modelo para uma nova realidade. Contudo, não entendemos como uma adaptação do modelo burocrático, mas sim como um novo modelo, mais complexo e ainda em construção, composto por características de organizações burocráticas, tecnologias e métodos da administração privada e crescentes iniciativas pós-burocráticas que fazem parte da constituição da realidade da AP no Brasil.

Ainda, pode-se explorar a ideia de formação de identidade nas estruturas burocráticas e pós-burocráticas que ocorrerão de maneiras distintas, buscando para tal associação aos estudos de teoria de carreira, de ordem tradicional/organizacional, mais associados ao ambiente burocrático e carreiras contemporâneas, de modo a ampliar a ótica dos estudos para além das fronteiras de uma única organização.

\section{REFERÊNCIAS}

ALVESSON, M.; WILLMOTT, H. Identity regulation as organization control: producing the appropriate individual. Journal of Management Studies, v. 39, n. 5, p. 619-644, 2002.

ANDION, C. Por uma nova interpretação das mudanças de paradigma na administração pública. Cadernos Ebape. BR, v. 10, n. 1, p. 1-19, 2012.

BARKER, J. R. Tightening the Iron Cage: concertive control in self-managing teams. Administrative Science Quarterly, v. 38, n. 3, p. 408, 1993.
BRESSER-PEREIRA, L. C. Da administração pública burocrática à gerencial. [S.l.: s.n.], 1996.

CAVAlCANTE, P. L. Trends in Public Administration after Hegemony of the New Public Management. Revista Do Serviço Público, v. 70, n. 2, p. 195-218, 2019.

CAVAlCANTE, P.; CARVAlHO, P. Profissionalização da burocracia federal brasileira (1995-2014): avanços e dilemas. Revista de Administração Pública, v. 51, n. 1, p. 1-26, 2017.

COURPASSON, D. Managerial strategies of domination. Power in soft bureaucracies. Organization studies, v. 21, n. 1, p. 141-161, 2000 .

DELLAGNELO, E. L.; MACHADO-DA-SILVA, C. Novas formas organizacionais: onde se encontram as evidências empíricas de ruptura com o modelo burocrático de organizações?. Organizações \& Sociedade, v. 7, n. 19, p. 1933, 2000.

DIMAGGIO, P. J.; POWELL, W. W.. A gaiola de ferro revisitada: isomorfismo institucional e racionalidade coletiva nos campos organizacionais. RAE-Revista de Administração de Empresas, v. 45, n. 2, p. 74-89, abr. 2005.

HERMAN, E. S. et al. Controle corporativo, poder corporativo. Nova Iorque: Cambridge University Press, 1981.

KALBERG, S. Max Weber: uma introdução. [S.l.]: Zahar, 2010.

KEINERT, T. M. M. Do aparelho estatal ao interesse público: crise e mudança de paradigmas na produção técnico-científica em administração pública no Brasil (1937-1997): análise de conteúdo dos artigos publicados na Revista do Serviço Público (1937-...) e Revista de Administração Pública (1967-...). 1999. 
Tese (Doutorado) - Escola de Administração de Empresas de São Paulo, São Paulo, 1999. MACHADO-DA-SILVA, C. L.; COSER, C. Rede de relações interorganizacionais no campo organizacional de Videira-SC. Revista de Administração Contemporânea, v. 10, n. 4, p. 9-45, 2006.

MEDEIROS, P. H. R. Do modelo racional-legal ao paradigma pós-burocrático: reflexões sobre a burocracia estatal. Organizações \& sociedade, v. 13, n. 37, p. 143-160, 2006.

SMIRCICH, L.; STUBBART, C. Strategic management in an enacted world. Academy of management Review, v. 10, n. 4, p. 724-736, 1985.

SOUSA, J. L.; PAIVA JUNIOR, F. G. Os novos tempos e a administração pública: as amarras da racionalidade instrumental e da regulação social. Revista Gestão Pública: Práticas e Desafios, Recife, v. 1, n. 1, p. 99-118, 2010.

SOUZA, C. Modernização do Estado e construção de capacidade burocrática para a implementação de políticas federalizadas. Revista de Administração Pública, v. 51, n. 1, p. 2745, 2017.

VASCONCELOS, F. C. Racionalidade, autoridade e burocracia: as bases da definição de um tipo organizacional pós-burocrático. Revista de Administração Pública, v. 38, n. 2, p. 199220, 2004.

VASCONCELOS, I. F. G.; PINOCHET, L. H. C. Poder, tecnologia e controle burocrático: uma análise crozieriana em uma empresa de informática do governo do estado do Paraná. Revista de Administração Pública, v. 38, n. 3, p. 465-480, 2004.

VIEIRA, M. M. F. Poder, objetivos e instituições como determinantes da definição de qualidade em organizações brasileiras e escocesas. Revista de Administração Contemporânea, v. 1, n. 1, p. 7-33, 1997.

WEBER, K.; GLYNN, M. A. Making sense with institutions: context, thought and action in Karl Weick's theory. Organization studies, v. 27, n. 11, p. 1639-1660, 2006.

WEBER, M. Economia e sociedade: fundamentos da sociologia compreensiva. Tradução Regis Barbosa. 4. ed. Brasília: Editora Universidade de Brasília, 2012. 